\title{
Early Cretaceous angiosperms and beetle evolution
}

\author{
Bo Wang ${ }^{1,2 *}$, Haichun Zhang ${ }^{2}$ and Edmund A. Jarzembowski ${ }^{2,3}$ \\ 1 Steinmann Institute, University of Bonn, Bonn, Germany \\ ${ }^{2}$ State Key Laboratory of Palaeobiology and Stratigraphy, Nanjing Institute of Geology and Palaeontology, Chinese Academy of Sciences, Nanjing, China \\ ${ }^{3}$ Department of Earth Sciences, The Natural History Museum, London, UK
}

\section{Edited by:}

Xin Wang, Nanjing Institute of Geology and Palaeontology, Chinese Academy of Sciences, China

\section{Reviewed by:}

Dong Ren, Capital Normal University, China

Conrad Christopher Labandeira, Smithsonian Institution, National Museum of Natural History, USA

\section{${ }^{*}$ Correspondence:}

Bo Wang, Steinmann Institute, University of Bonn, Nußallee 8, 53115 Bonn, Germany

e-mail: savantwang@gmail.com
The Coleoptera (beetles) constitute almost one-fourth of all known life-forms on earth. They are also among the most important pollinators of flowering plants, especially basal angiosperms. Beetle fossils are abundant, almost spanning the entire Early Cretaceous, and thus provide important clues to explore the co-evolutionary processes between beetles and angiosperms. We review the fossil record of some Early Cretaceous polyphagan beetles including Tenebrionoidea, Scarabaeoidea, Curculionoidea, and Chrysomeloidea. Both the fossil record and molecular analyses reveal that these four groups had already diversified during or before the Early Cretaceous, clearly before the initial rise of angiosperms to widespread floristic dominance. These four beetle groups are important pollinators of basal angiosperms today, suggesting that their ecological association with angiosperms probably formed as early as in the Early Cretaceous. With the description of additional wellpreserved fossils and improvements in phylogenetic analyses, our knowledge of Mesozoic beetle-angiosperm mutualisms will greatly increase during the near future.

Keywords: beetle, angiosperm, Cretaceous, pollinator, fossil, coevolution

\section{INTRODUCTION}

The Coleoptera (beetles) constitute almost one-fourth of all known life-forms on earth, and their extraordinary species richness is probably due to the elevated survival of lineages and their sustained diversification in a variety of niches (Hunt et al., 2007; Ikeda et al., 2012). Beetles are among the most important pollinators of flowering plants, especially basal angiosperms (Thien etal., 2009), and they are also thought to be among the earliest insect visitors and pollinators of angiosperms (Bernhardt, 2000). The diversification of some of the most species rich extant lineages of beetles may have been driven by co-radiations with angiosperms (Farrell, 1998). In addition, the early partnerships between angiosperms and pollinating insects were also major factors in the currently recognized radiation of the angiosperms $\mathrm{(Hu}$ et al., 2008).

The Early Cretaceous is a time of important developments in angiosperms (Friis et al., 2010). The earliest unequivocal remains of angiosperms are generally thought to be pollen grains in the early Hauterivian $(\sim 130 \mathrm{Ma}$; Friis et al., 2010$)$, despite claims based on other fossils and molecular analyses (Bell etal., 2010; Wang, 2010; Smith etal., 2011). The fossil record shows that angiosperms rose to dominance during the AlbianCenomanian (112-93.6 Ma), and become forest dominants during the Campanian-Maastrichtian (84-65.5 Ma; Peralta-Medina and Falcon-Lang, 2012). The angiosperm radiations provided new food resources and habitats, and had a profound effect on beetles and other insects.

The Early Cretaceous is also an important period for the evolution of beetles, including the decline of archostematan beetles, ecological success of adephagan beetles, and the first appearance and divergence of some major polyphagan lineages (Ponomarenko, 2002). The Scarabaeoidea, Tenebrionoidea, Curculionoidea, and Chrysomeloidea are among the commonest pollinators of most extant basal angiosperms (Bernhardt, 2000; Thien et al., 2009). The probable impact of floristic changes on beetles during the Early Cretaceous has been widely accepted, but supporting fossils are still very few (Labandeira, 1998; Grimaldi, 1999; Labandeira and Currano, 2013). Recently abundant Early Cretaceous fossils have been described and our knowledge of the evolution of beetles has improved greatly. These new fossils, therefore, provide important clues to explore the co-evolutionary process between beetles and angiosperms. In this paper, we review the fossil record and early evolution of these four Early Cretaceous polyphagan groups, and briefly discuss their probable ecological associations with early angiosperms.

\section{FOSSIL RECORD SCARABAEOIDEA}

Scarabaeoidea (scarab beetles) is a cosmopolitan monophyletic superfamily comprising around 35,000 described species (Scholtz and Grebennikov, 2005). They are commonly stout-bodied beetles, sometimes with bright metallic colors, measuring between 1.5 and $160 \mathrm{~mm}$ long (Bai et al., 2012). Their adult fossils can be distinguished by the following features: distinctive, clubbed antennae; front legs broad and adapted for digging; and meso- and metatibia commonly with transverse, setose, or spinose keels on an outer surface (Krell, 2006). The earliest unambiguous fossils, represented by several families, are recorded from the Middle Jurassic of Daohugou, China and the Upper Jurassic of Karatau, Kazakhstan (Nikolajev et al., 2011; Bai et al., 2012). The fossil record of Scarabaeoidea has been reviewed by Krell (2006) and Nikolajev (2007), and the biodiversity pattern in terms of species numbers from the Cenozoic and Mesozoic eras is summarized by Bai et al. (2012). The overwhelming majority of fossil scarabaeoids have been discovered from the Early Cretaceous of China, Russia, and Brazil, most of which require detailed descriptions (Krell, 2006; 
Zhang et al., 2010). A recent molecular analysis suggests that most scarab families may have originated in the Cretaceous (McKenna and Farrell, 2009). However, the discovery of scarab fossils from the Middle to Late Jurassic indicate that they are much older than their estimated divergence times calculated from previous molecular evidence (Nikolajev et al., 2011; Bai et al., 2012), and most of which belong to families that have been found in the Early Cretaceous (Krell, 2006; Nikolajev, 2007). Consequently, most families of Scarabaeoidea originated significantly before the mid-Cretaceous angiosperm radiation, probably during the Middle-Late Jurassic.

\section{TENEBRIONOIDEA}

The Tenebrionoidea (including darkling beetles) is one of the most abundant superfamilies of beetles, comprising about 35,000 described species in 30 families worldwide (Hunt et al., 2007). Adult tenebrionoids are distinguished by an aedeagus of heteromeroid condition, trochanterofemoral articulations oblique, and tarsal formulae of 5-5-4, 4-4-4, 3-4-4 or rarely 3-3-3 (Lawrence et al., 2010). The oldest definite records of this group are mordellid-like beetles from the Middle Jurassic of Daohugou, China, and several families are also described from the Upper Jurassic of Karatau, Kazakhstan (see annotated list of Mesozoic tenebrionoid beetles given by Wang and Zhang, 2011).

The phylogenetic relationships among the families of Tenebrionoidea are still poorly understood (Beutel and Friedrich, 2005; Lawrence et al., 2010). The Mordellidae are thought to be among the most basal groups of Tenebrionoidea based on molecular analysis (McKenna and Farrell, 2009). Some Early Cretaceous fossils have been attributed to the extinct subfamily "Praemordellinae" which was placed in Mordellidae on the following characters: tarsal formula 5-5-4; body wedge-shaped, elongate, and arched with fine pubescence; head deflexed, constricted behind the eyes to form a neck; and abdomen (not pygidium) extending beyond elytra (Liu et al., 2007). These characters are not autapomorphies of Mordellidae, and all can be found in the Ripiphoridae and Scraptiidae. Instead, these characters suggest Praemordellidae is a stem group which probably includes ancestors of Mordellidae and of other groups, such as Ripiphoridae. The earliest definitive Mordellidae are reported from the earliest Cenomanian (Late Cretaceous) Burmese amber (Grimaldi et al., 2002; Shi et al., 2012). The adults of modern Mordellidae are phytophagous, apparently feeding on the pollen of many plants, especially of umbellifers (Apiaceae) and composites (Asteraceae; Jackman and Lu, 2002). In the Cretaceous, fossils appear relatively diverse and show that several advanced tenebrionoids, such as Rhipiphoridae and Tenebrioninae, definitely occur during this interval (e.g., Perrichot et al., 2004; Liu et al., 2007; Kirejtshuk et al., 2012). Both fossils and molecular analysis suggest that most families of Tenebrionoidea originated during or before the Early Cretaceous.

\section{CURCULIONOIDEA}

The Phytophaga represents the largest radiation of beetles (Coleoptera), and is the second most species rich lineage of plant-feeding animals after the Lepidoptera (Grimaldi and Engel, 2005). It is a well-defined monophyletic group supported by both morphological and molecular data, comprising the reciprocally monophyletic groups Curculionoidea (weevils) and Chrysomeloidea (longhorn and leaf beetles; Marvaldi et al., 2009).

The Curculionoidea (weevils), containing about 62,000 species within 5,800 described genera, are the most diverse group of beetles (Oberprieler et al., 2007). They are easily recognizable by a rostrum or snout projecting forward and downward from the head, with mandibles or jaws positioned at the rostral tip (Thompson, 1992). Weevils are essentially phytophagous beetles, and some are serious pests of agricultural crops and stored food products. Their fossil record is quite extensive and constitutes the dominant group among the Phytophaga in the Mesozoic fossil record (Arnoldi et al., 1977). The oldest weevils, belonging to the Nemonychidae, occur in the Middle Jurassic of Daohugou, China (undescribed specimens) and Upper Jurassic of Karatau, Central Asia (Oberprieler et al., 2007). An updated list of Mesozoic fossils is provided by Soriano et al. (2006) and Legalov (2012). Abundant weevils were recorded from the Lower Cretaceous of Russia, Spain, China, and Brazil (Soriano et al., 2006; Davis et al., 2013). However, no weevil is known from the Triassic to Early Jurassic, although there are many other beetle fossils of the same age (Gratshev and Zherikhin, 2003). One lineage, the Obrieniidae, was thought to have a relationship to the Curculionidae, but now is thought to be an example of morphological convergence or parallel evolution in an unrelated group (Gratshev and Zherikhin, 2003; Oberprieler et al., 2007).

The Nemonychidae, consisting of 21 living genera and 76 known species, is a small, relict family of weevils (Kuschel, 1983; Oberprieler et al., 2007). They are the most primitive weevils, with the most plesiomorphic features of all extant lineages. These beetles are most diverse in the Australian and Neotropical regions, with fewer species occurring in the Nearctic and Palaearctic regions. The Nemonychidae are predominantly associated with conifers, especially the family Araucariaceae, while the Pinaceae provide their common hosts in the northern hemisphere. The Nemonychidae are presumed to retain the ancestral life style of weevils, including their mobile larvae living freely (ectophytically) among the sporophylls within dehiscing male conifer strobili (cones), feeding on pollen in open pollen sacs and moving between cones (Oberprieler et al., 2007).

The Anthribidae, Attelabidae, Caridae, and Curculionidae are definitely known from the Early Cretaceous (Oberprieler et al., 2007; Kirejtshuk et al., 2009; Cognato and Grimaldi, 2010; Santos et al., 2011). Estimated divergence times indicate that initial diversification of most families occurred on gymnosperms during the Jurassic, and a massive diversification even probably began in the mid-Cretaceous (McKenna et al., 2009; Jordal et al., 2011).

\section{CHRYSOMELOIDEA}

Most chrysomelid beetles belong to two unusually diverse families: Chrysomelidae (leaf beetles) with more than 35,000 described species, and Cerambycidae (longhorn beetles) with over 20,000 described species (Marvaldi et al., 2009). The Chrysomelidae are typically small to medium-size beetles with an elongate-oval body form, and adults that commonly consume leaves or floral elements (Riley et al., 2002). Cerambycidae are generally large insects with raised antennal insertions and long antennae (Turnbow and Thomas, 2002). Adult Cerambycidae feed on leaves, meristematic 
cambial tissue or pollen, and their larvae generally mine the phloem of trees or bore into heartwood (Hanks, 1999). Almost all species of extant Chrysomeloidea are phytophagous, and most phytophagous Chrysomeloidea feed on angiosperms (Farrell, 1998). Their great diversity has been commonly attributed to co-radiation with early angiosperms (Farrell, 1998; Wilf et al., 2000; Farrell and Sequeira, 2004; but see Reid, 2000).

The fossil record of Mesozoic Chrysomeloidea is extremely poor (Grimaldi and Engel, 2005), and is reviewed recently by Wang et al. (2013). Several Late Jurassic fossils from Karatau, Kazakhstan probably are attributed to the Chrysomeloidea, but require further investigation as to their systematic position. Besides these Jurassic fossils, only two fossils of Early Cretaceous Chrysomeloidea are known. The earliest known Cerambycidae (Prioninae) and Chrysomelidae (Bruchinae) are from the Early Cretaceous of China and the Late Cretaceous Canadian amber respectively (Poinar, 2005; Wang et al., 2013). Estimated divergence times suggest that most modern families of Chrysomeloidea originated during the Jurassic period (Farrell, 1998; McKenna and Farrell, 2006, 2009; Hunt et al., 2007; Wang et al., 2013). Chrysomelidae may occur in the Middle Jurassic (Wang et al., 2013), and all major subfamilies of Chrysomelidae originated before the beginning of the Albian (Kergoat et al., 2011; Wang et al., 2013).

\section{PROBABLE BEETLE-ANGIOSPERM ASSOCIATIONS}

Mutualisms between fossil insects and plants are among the most interesting biological associations. The most compelling evidence of early interactions between insects and the reproductive organs of plants is in the form of pollen preserved in the coprolites or guts of fossil insects (Bronstein et al., 2006; Labandeira et al., 2007). The earliest records of pollen consumption are from permineralized coprolites of medullosan seed-fern pollen and tree-fern spores from the Late Pennsylvanian Calhoun Coal (Labandeira, 2006), and from generalized polyneopterans from the Permian with gymnosperm pollen preserved in their guts (Rasnitsyn and Krassilov, 1996). Although some pollen grains were found in the guts of several Mesozoic groups, such as wasps and crickets, no record is reported from Mesozoic beetles. The preservation of gut contents appears unrelated to the preservational quality of the insects. For example, no gut contents hitherto have been found in the well-preserved Jurassic Daohugou specimens. Further investigation of additional insects from various Mesozoic fossil localities may reveal direct evidence.

Other direct evidence for the evolution of insect pollination is the preservation in fossil angiosperm flowers of specialized structures that attract favored insect partners and promote pollen delivery (e.g., Hartkopf-Froder et al., 2012). The Early Cretaceous evidence is, however, very scarce due to the rarity of well-preserved three-dimensional flowers. So far, only Gandolfo et al. (2004) offer a compelling argument that the pollination of members of the Nymphaeaceae by beetles represents an ancient mutualistic partnership which can be traced back to the mid-Cretaceous.

Indirect evidence include the structure of the pollen-collecting mouthparts of beetles. Modern flower-visiting beetles often possess conspicuous eyes and combs of setae on the mandibles, palps or other mouthparts, for example in the Oedemeridae and Mordellidae (Barth, 1985; Krenn et al., 2005). Bernhardt (1996) reviews the three different mechanisms that beetles may employ to digest the contents of pollen grains. Some structures of fossil mouthparts clearly are visible in amber-entombed beetles (e.g., Kirejtshuk et al., 2009) as well as occasional specimens from well-preserved compressions (e.g., Wang et al., 2012). Further examination of the mouthparts from some probable Mesozoic pollen-feeding beetles is needed.

Other indirect evidence consists of observations on pollination systems of the most basal angiosperms, including the ANITA group and Magnoliidae. Nine families, consisting of Scarabaeidae; Mordellidae, Oedemeridae, and Scraptiidae within Tenebrionoidea; Cerambycidae and Chrysomelidae within Chrysomeloidea; Curculionidae; Nitidulidae; Staphylinidae, are pollen vectors of specialized flowers produced by magnoliids. Two families, Scarabaeidae and Chrysomelidae, are pollinators of the Nymphaeaceae (Bernhardt, 2000; Bernhardt et al., 2003). Ervik and Knudsen (2003) have also presented evidence that members of the Nymphaeaceae are pollinated by scarabaeid beetles. As discussed above, at least four lineages of beetle pollinators of extant basal angiosperms occurred minimally by the Early Cretaceous, suggesting that their ecological association with angiosperms probably appeared at the same time or earlier with gymnospermous groups and even ferns. Their phytophagousadapted structures, including herbivory or pollination, were probably used first on a variety of gymnospermous groups and even ferns (Labandeira et al., 2007). A similar condition is present in other insects such as scorpionflies (Ren et al., 2009) and thrips (Peñalver et al., 2012). The beetle adaptation on gymnospermous groups before the rise of angiosperms is beyond the scope of this paper, and will be discussed in the following paper.

Phylogenetic analysis based on fossil, morphological and molecular data is a powerful tool for investigating the evolution of beetle-angiosperm interactions (McKenna, 2011). Detailed investigations of the Tenebrionoidea and Scarabaeoidea are lacking, but some progress has been made on the Phytophaga. Molecular analysis of the Curculionoidea indicates that their diversification into most family level lineages took place during the Jurassic and a subsequent radiation closely followed the currently recognized rise of the angiosperms (McKenna et al., 2009; but see Franz and Engel, 2010). A similar scenario has also been proposed for the curculionoid sister group, Chrysomeloidea (Wang et al., 2013). Initial diversification of the Chrysomeloidea most probably occurred on gymnosperms in the mid-Mesozoic, when conifers and other gymnospermous plants dominated forest and other ecosystems such as open-canopied woodland, and perhaps some wetlands (Wang et al., 2013). The diversification of the angiosperm-associated subfamilies widely corresponds with the rapid increase of angiosperm productivity and the rise of angiosperm-dominated forests which may have provided new, diversified ecological niches as well as abundant food, and facilitated the radiation of the Chrysomelidae (Wang et al., 2013). Consequently, the Chrysomeloidea and Curculionoidea may have a similar evolutionary trajectory: both show high lineage survival rates and the rise of the angiosperms contributed to their modern high diversity. Nevertheless, because of uncertainties about higher-level relationships and divergence times in these beetle lineages, the detailed evolutionary history of beetle-angiosperm interactions remains unclear. 


\section{CONCLUSION}

Scarabaeoidea, Tenebrionoidea, Curculionoidea, and Chrysomeloidea currently are among the common pollinators of the most basal angiosperms. Both the fossil record and molecular analyses reveal that these four groups had already diversified during or before the Early Cretaceous. Their divergence is clearly before the currently recognized radiation of angiosperms and achieved widespread floristic dominance, suggesting that their ecological association with angiosperms probably formed as early as the Lower Cretaceous. In addition to small beetles, other common pollinator groups were around at this time pollinating basal (ANITA-grade) angiosperms, such as thrips, nematoceran flies, moths, scorpionflies, and small parasitoid wasps (Labandeira, 2005; Labandeira and Currano, 2013). In this review we have only scratched the surface of the evolution of Early Cretaceous beetle-angiosperm mutualisms. However, the Early Cretaceous associations between beetles and angiosperms are far from completely known. Thanks

\section{REFERENCES}

Arnoldi, L. V., Zherikhin, V. V., Nikritin, L. M., and Ponomarenko, A. G. (1977). Mesozoic Coleoptera. Tr. Paleont. Inst. 161, 1-204.

Bai, M., Ahrens, D., Yang, X. K., and Ren, D. (2012). New fossil evidence of the early diversification of scarabs: Alloioscarabaeus cheni (Coleoptera: Scarabaeoidea) from the Middle Jurassic of Inner Mongolia, China. Insect Sci. 19, 159171. doi: 10.1111/j.1744-7917.2011. 01460.x

Barth, F. B. (1985). Insects and Flowers: The Biology of a Partnership. Princeton: Princeton University Press.

Bell, C. D., Soltis, D. E., and Soltis, P. (2010). The age and diversification of angiosperms re-revisited. Am. J. Bot. 97, 1296-1303. doi: 10.3732/ajb.0900346

Bernhardt, P. (1996). "Anther adaptation in animal pollination," in The Anther: Form, Function, and Phylogeny, eds W. G. D'Arcy and R. C. Keating (Cambridge: Cambridge University Press), 192-220.

Bernhardt, P. (2000). Convergent evolution and adaptive radiation of beetle-pollinated angiosperms. Plant Syst. Evol. 222, 293-320. doi: 10.1007/BF00984108

Bernhardt, P., Sage, T., Weston, P., Azuma, H., Lam, M., Thien, L. B., et al. (2003). The pollination of Trimenia moorei (Trimeniaceae): floral volatiles, insect/wind vectors, and stigmatic self-incompatibility in a basal angiosperm. Ann. Bot. 92, 445-458. doi: 10.1093/aob/ $\operatorname{mcg} 157$

Beutel, R. G., and Friedrich, F. (2005) Comparative study of larvae of
Tenebrionoidea (Coleoptera: Cucujiformia). Eur. J. Entomol. 102, 241264.

Bronstein, J. L., Alarcón, R., and Geber, M. (2006). The evolution of plantinsect mutualisms. New Phytol. 172, 412-428. doi: 10.1111/j.1469-8137. 2006.01864.x

Cognato, A. I., and Grimaldi, D. (2010). One hundred million years of morphological conservation in a bark beetle (Coleoptera: Curculionidae: Scolytinae). Syst. Entomol. 34, 93100. doi: $10.1111 / \mathrm{j} .1365-3113.2008$ 00441. $\mathrm{x}$

Davis, S. R., Engel, M. S., Legalov, A., and Ren, D. (2013). Weevils of the Yixian formation, China (Coleoptera: Curculionoidea): phylogenetic considerations and comparison with other Mesozoic faunas. J. Syst. Palaeontol. 11, 399429. doi: 10.1080/14772019.2012 691906

Ervik, F., and Knudsen, J. T. (2003). Water lilies and scarabs: faithful partners for 100 million years? Biol. J. Linn. Soc. 80, 539543. doi: 10.1046/j.1095-8312.2003. 00258.x

Farrell, B. D. (1998). "Inordinate fondness" explained: why are there so many beetles? Science 281, 555-559. doi: 10.1126/science.281. 5376.555

Farrell, B. D., and Sequeira, A. S. (2004). Evolutionary rates in the adaptive radiation of beetles on plants. Evolution 58, 1984-2001.

Franz, N. M., and Engel, M. S. (2010). Can higher-level phylogenies of weevils explain their evolutionary success? A critical review. Syst. Entomol. 35, 597-606. doi: 10.1111/j.13653113.2010.00534.x

to the discovery of better preserved fossils and improvements in phylogenetic analysis, our knowledge of Mesozoic beetleangiosperm mutualisms should greatly expanded in the immediate future.

\section{ACKNOWLEDGMENTS}

We thank Xin Wang for inviting us to contribute this review. We also thank Junfeng Zhang, A. G. Ponomarenko, R. G. Oberprieler, and D. D. McKenna for helpful discussions, and C. C. Labandeira and Dong Ren for reviewing the manuscript and constructive criticisms. This work was supported by the National Basic Research Program of China (Grant No. 2012CB821900), and the National Natural Science Foundation of China (Grant Nos. 41002006, J1210006). Bo Wang was supported by the Research Fellowship from the Alexander von Humboldt Foundation. Edmund. A. Jarzembowski was supported by the Chinese Academy of Sciences Visiting Professorship for Senior International Scientists (Grant No. 2011t2z04).

Friis, E. M., Pedersen, K. R., and Crane, P. R. (2010). Diversity in obscurity: fossil flowers and the early history of angiosperms. Philos. Trans. R. Soc. Lond. B Biol. Sci. 365, 369-382. doi: 10.1098/rstb.2009. 0227

Gandolfo, M. A., Nixon, K. C., and Crepet, W. L. (2004). Cretaceous flowers of Nymphaeaceae and implications for complex insect entrapment pollination mechanisms in early angiosperms. Proc. Natl. Acad. Sci. U.S.A. 101, 8056-8060. doi: 10.1073/pnas. 0402473101

Gratshev, V. G., and Zherikhin, V. V. (2003). The fossil record of weevils and related beetle families (Coleoptera, Nemonychidae). Acta Zool. Cracov. 46 (Suppl. Fossil Insects), 129-138.

Grimaldi, D. (1999). The coradiations of pollinating insects and angiosperms in the Cretaceous. Ann. Mo. Bot. Gard. 86, 373-406. doi: $10.2307 / 2666181$

Grimaldi, D., and Engel, M. S. (2005). Evolution of the Insects. Cambridge, UK: Cambridge University Press.

Grimaldi, D., Engel, M. S., and Nascimbene, P. C. (2002). Fossiliferous Cretaceous amber from Myanmar (Burma): its rediscovery, biotic diversity, and paleontological significance. Am. Mus. Novit. $3361, \quad 1-72$. doi: 10.1206/0003 0082(2002)361<0001:FCAFMB $>2.0$. $\mathrm{CO} ; 2$

Hanks, L. M. (1999). Influence of the larval host plant on reproductive stages of cerambycid beetles. Annu. Rev. Entomol. 44, 483-505. doi: 10.1146/annurev.ento.44.1.483
Hartkopf-Froder, C., Rust, J., Wappler T., Friis, E. M., and Viehofen, A. (2012). Mid-Cretaceous charred fossil flowers reveal direct observation of arthropod feeding strategies. Biol. Lett. 8, 295-298. doi: 10.1098/rsbl. 2011.0696

Hu, S., Dilcher, D. L., Jarzen, D. M., and Taylor, D. W. (2008). Early steps of angiosperm - pollinator coevolution. Proc. Natl. Acad. Sci. U.S.A. 105, 240-245. doi: 10.1073/pnas. 0707989105

Hunt, T., Bergsten, J., Levkanicova, Z., Papadopoulou, A., John, O. S., Wild, R., etal. (2007). A comprehensive phylogeny of beetles reveals the evolutionary origins of a superradiation. Science 318, 1913-1916. doi: 10.1126/science. 1146954

Ikeda, H., Nishikawa, M., and Sota, T. (2012). Loss of flight promotes beetle diversification. Nat. Commun. 3, 648. doi: 10.1038/ ncomms 1659

Jackman J. A., and Lu, W. H. (2002). "101. MORDELLIDAE Latreille 1802," in American Beetles, eds R. H. Arnett, M. C. Thomas, P. E. Skelley, and J. H. Frank (Boca Raton, FL: CRC Press), 423-430.

Jordal, B. H., Sequeira, A. S., and Cognato, A. I. (2011). The age and phylogeny of wood boring weevils and the origin of subsociality. Mol. Phylogenet. Evol. 59, 708-724. doi: 10.1016/j.ympev.2011. 03.016

Kergoat, G. J., Le Ru, B. P., Genson, G., Cruaud, C., Couloux, A., and Delobel, A. (2011). Phylogenetics, species boundaries, and timing of resource tracking in a highly specialized group of seed beetles 
(Coleoptera: Chrysomelidae: Bruchinae). Mol. Phylogenet. Evol. 59, 746-760. doi: 10.1016/j.ympev.2011. 03.014

Kirejtshuk, A. G., Azar, D., Beaver, R. A., Mandelshtam, M. Y., and Nel, A. (2009). The most ancient bark beetle known: a new tribe, genus and species from Lebanese amber (Coleoptera, Curculionidae, Scolytinae). Syst. Entomol. 34, 101112. doi: 10.1111/j.1365-3113.2008 00442.x

Kirejtshuk, A. G., Nabozhenko, M V., and Nel, A. (2012). First Mesozoic representative of the subfamily Tenebrioninae (Coleoptera, Tenebrionidae) from the Lower Cretaceous of Yixian (China, Liaoning). Entomol. Rev. 92, 97-100. doi: 10.1134/ S0013873812010101

Krell, F. T. (2006). Fossil record and evolution of Scarabaeoidea (Coleoptera: Polyphaga). Coleopt. Bull. 60, 120-143. doi: 10.1649/0010-065X (2006)60[120:FRAEOS]2.0.CO;2

Krenn, H. W., Plant, J. D., and Szucsich, N. U. (2005). Mouthparts of flower-visiting insects. Arthropod Struct. Dev. 34, 1-40. doi: 10.1016/j.asd.2004.10.002

Kuschel, G. (1983). Past and present of the relict family Nemonychidae (Coleoptera, Curculionoidae). GeoJournal 7, 499-504.

Labandeira, C. C. (1998). The role of insects in Late Jurassic to Middle Cretaceous ecosystems. N. M. Mus. Nat. Hist. Sci. Bull. 14, 105-124.

Labandeira, C. C. (2005). "Fossil history of the Diptera and their associations with plants," in The Evolutionary Biology of Flies, eds B. Wiegmann and D. Yeates (New York: Columbia University Pres), 217-273.

Labandeira, C. C. (2006). Silurian to Triassic plant and insect clades and their associations: new data, a review, and interpretations. Arthropod Syst. Phylogeny 64, 53-94.

Labandeira, C. C., and Currano E. D. (2013). The fossil record of plant-insect dynamics. Annu. Rev. Earth Planet. Sci. 41, 13.1-13.25. doi: 10.1146/annurev-earth-050212124139

Labandeira, C. C., Kvaèek, J., and Mostovski, M. B. (2007). Pollination fluids, pollen, and insect pollination of Mesozoic gymnosperms. Taxon 56, 663-695. doi: 10.2307/ 25065853

Lawrence, J. F., Pollock, D. A., and S̃lipiñski, S. A. (2010). "Tenebrionoidea," in Handbook of Zoology, Vol. IV, Arthropoda, Part II, Insecta, Coleoptera, Vol. 2: Systematics (Part 2), eds R. A. B. Leschen, R. G. Beutel, and J. F. Lawrence (Berlin: Walter De Gruyter), 487-491.

Legalov, A. A. (2012). Fossil history of Mesozoic weevils (Coleoptera: Curculionoidea). Insect Sci. 19, 683698. doi: 10.1111/j.1744-7917.2012. 01508.x

Liu, M., Lu, W. H., and Ren, D. (2007). A new fossil mordellid (Coleoptera: Tenebrionoidea: Mordellidae) from the Yixian formation of Western Liaoning Province, China. Zootaxa 1415, 49-56.

Marvaldi, A. E., Duckett, C. N., Kjer, K. M., and Gillespie, J. J. (2009). Structural alignment of $18 \mathrm{~S}$ and $28 \mathrm{~S}$ rDNA sequences provides insights into the phylogeny of Phytophaga and related beetles (Coleoptera: Cucujiformia). Zool. Scr. 38, 6377. doi: 10.1111/j.1463-6409.2008. 00360.x

McKenna, D. D. (2011). Towards a temporal framework for "inordinate fondness": reconstructing the macroevolutionary history of beetles (Coleoptera). Entomol. Am. 117, 28-36. doi: 10.1664/10-RA013.1

McKenna, D. D., and Farrell, B. (2006). Tropical forests are both evolutionary cradles and museums of leaf beetle diversity. Proc. Natl. Acad. Sci. U.S.A. 103, 10947-10951. doi: 10.1073/pnas. 0602712103

McKenna, D. D., and Farrell, B. (2009). "Beetles (Coleoptera)," in The Timetree of Life, eds S. B. Hedges and K. Kumar (Oxford: Oxford University Press), 278-289

McKenna, D. D., Sequeira, A. S., Marvaldi, A. E., and Farrell, B. D. (2009). Temporal lags and overlap in the diversification of weevils and flowering plants. Proc. Natl. Acad. Sci. U.S.A. 106, 7083-7088. doi: 10.1073/pnas.0810618106

Nikolajev, G. V. (2007). The Mesozoic Stage of Evolution of the Scarabaeoid Beetles (Insecta: Coleoptera: Scarabaeoidea). Almaty: Kazak Universiteti.

Nikolajev, G. V., Wang, B., Liu Y., and Zhang H. C. (2011). Stag beetles from the Mesozoic of Inner Mongolia, China (Scarabaeoidea: Lucanidae). Acta Palaeontol. Sin. 50, 41-47.

Oberprieler, R. G., Marvaldi, A. E., and Anderson, R. S. (2007). Weevils, weevils, weevils everywhere. Zootaxa 1668, 491-520.

Peñalver, E., Labandeira, C. C., Barrón, E., Delclòs, X., Nel, A., Nel, P., et al. (2012). Thrips pollination of Mesozoic gymnosperms. Proc. Natl. Acad. Sci. U.S.A. 109, 8623-8628. doi: 10.1073/pnas.1120499109
Peralta-Medina, E., and Falcon-Lang, H. J. (2012). Cretaceous forest composition and productivity inferred from a global fossil wood database. Geology 40, 219-222. doi: 10.1130/G32733.1

Perrichot, V., Nel, A., and Néraudeau, D. (2004). Two new wedge-shaped beetles in Albo-Cenomanian ambers of France (Coleoptera: Ripiphoridae: Ripiphorinae). Eur. J. Entomol. 101, 577-581.

Poinar, G. O. (2005). A Cretaceous palm bruchid, Mesopachymerus antiqua, n. gen., n. sp. (Coleoptera: Bruchidae: Pachymerini) and biogeographical implications. Proc. Entomol. Soc. Wash. 107, 392-397.

Ponomarenko, A. G. (2002). "Superorder Scarabaeidea Laicharting, 1781. Order Coleoptera Linné, 1758. The beetles," in History of insects, eds A. P. Rasnitsyn and D. L. J. Quicke (Dordrecht: Kluwer Academic Publisher), 164-176.

Rasnitsyn, A. P., and Krassilov, V. A. (1996). Pollen in the gut contents of fossil insects as evidence of coevolution. Paleontol. J. 30, 716-722.

Reid, C. A. M. (2000). Spilopyrinae Chapuis: a new subfamily in the Chrysomelidae and its systematic placement (Coleoptera). Invertebr. Taxon. 14, 837-862. doi: 10.1071/IT00042

Ren, D., Labandeira, C. C., SantiagoBlay, J. A., Rasnitsyn, A. P. Shih, C. K., Bashkuev, A., et al. (2009). A probable pollination mode before angiosperms: eurasian, long-proboscid scorpionflies. Science 326, 840-847. doi: 10.1126/science. 1178338

Riley, E. G., Clark, S. M., Flowers, R. W., and Gilbert, A. J. (2002). "Family 124. Chrysomelidae Latreille 180," in American Beetles, eds R. H. Arnett, M. C. Thomas, P. E. Skelley, and J. H. Frank (Boca Raton, FL: CRC Press), 617-691.

Santos, M. F. D. A., Mermudes, J. R. M., and Fonseca, V. M. M. D. (2011). A specimen of Curculioninae (Curculionidae, Coleoptera) from the Lower Cretaceous, Araripe Basin, north-eastern Brazil. Palaeontology 54, 807-814. doi: 10.1111/j.14754983.2011.01057.x

Scholtz, C. H., and Grebennikov, V. V. (2005) "Scarabaeioidea Latreille, 1802," in Handbook of Zoology, Vol. IV, Arthropoda, Part II, Insecta, Coleoptera, Vol. 1: Morphology and Systematics (Archostemata, Adephaga, Myxophaga, Polyphaga partim), eds R.G. Beutel and R. A. B. Leschen (Berlin: Walter De Gruyter), 367425
Shi, G. H., Grimaldi, D. A., Harlow, G. E., Wang, J., Wang, J., Yang, M. C., et al. (2012). Age constraint on Burmese amber based on U-Pb dating of zircons. Cretaceous Res. 37, 155-163. doi: 10.1016/j.cretres.2012. 03.014

Smith, S. A., Beaulieu, J., Stamatakis, A., and Donoghue, M. J. (2011). Understanding angiosperm diversification using large and small phylogenies. Am. J. Bot. 98, 404-414. doi: 10.3732/ajb. 1000481

Soriano, C., Gratshev, V. G., and Delclòs, X. (2006). New Early Cretaceous weevils (Insecta, Coleoptera, Curculionoidea) from El Montsec, Spain. Cretaceous Res. 27, 555-564. doi: 10.1016/j.cretres.2005. 10.015

Thien, L. B., Bernhardt, P., Devall, M. S., Chen, Z. D., Luo, Y. B., Fan, J. H., et al. (2009). Pollination biology of basal angiosperms (ANITA grade). Am. J. Bot. 96, 166-182. doi: 10.3732/ajb.0800016

Thompson, R. T. (1992). Observations on the morphology and classification of weevils (Coleoptera, Curculionoidea) with a key to major groups. J. Nat. Hist. 26, 835-891. doi: 10.1080/ 00222939200770511

Turnbow, R. H. Jr., and Thomas, M. C. (2002). "Family 91. Cerambycidae Leach 1815," in American Beetles, eds R. H. Arnett, M. C. Thomas, P. E. Skelley, and J. H. Frank (Boca Raton, FL: CRC Press), 568-601.

Wang, B., Ma, J. Y., McKenna, D., Yan, E. V., Zhang, H. C., and Jarzembowski, E. A. (2013). The earliest known longhorn beetle (Cerambycidae: Prioninae) and implications for the early evolution of Chrysomeloidea. J. Syst. Palaeontol. doi: 10.1080/14772019. 2013.806602

Wang, B., and Zhang, H. C. (2011). The oldest Tenebrionoidea (Coleoptera) from the Middle Jurassic of China. J. Paleontol. 85, 266-270. doi: 10.1666/09-088.1

Wang, B., Zhang H. C., and Ponomarenko, A. G. (2012). Mesozoic Trachypachidae (Insecta: Coleoptera) from China. Palaeontology 55, 341353. doi: 10.1111/j.1475-4983.2012. 01128.x

Wang, X. (2010). The Dawn Angiosperms: Uncovering the Origin of Flowering Plants. Berlin: SpringerVerlag. doi: 10.1007/978-3-64201161-0

Wilf, P., Labandeira, C. C., Kress, W. J., Staines, C. L., Windsor, D. M., Allen, A. L., et al. (2000). Timing the radiation of leaf beetles: 
hispines on gingers from the latest Cretaceous to recent. Science 289, 291-294. doi: 10.1126/science.289. 5477.291

Zhang, H. C., Wang, B., and Fang, Y. (2010). Evolution of insects in diversity through the Jehol Biota. Sci. China Earth Sci. 53, 1908 1917. doi: 10.1007/s11430-0104098-5
Conflict of Interest Statement: The authors declare that the research was conducted in the absence of any commercial or financial relationships that could be construed as a potential conflict of interest.

Received: 10 June 2013; accepted: 26 August 2013; published online: 12 September 2013.
Citation: Wang B, Zhang $H$ and Jarzembowski EA (2013) Early Cretaceous angiosperms and beetle evolution. Front. Plant Sci. 4:360. doi 10.3389/fpls.2013.00360

This article was submitted to Plant Evolution and Development, a section of the journal Frontiers in Plant Science.

Copyright (c) 2013 Wang, Zhang and Jarzembowski. This is an open-access article distributed under the terms of the Creative Commons Attribution License (CC BY). The use, distribution or reproduction in other forums is permitted, provided the original author(s) or licensor are credited and that the original publication in this journal is cited, in accordance with accepted academic practice. No use, distribution or reproduction is permitted which does not comply with these terms. 